\title{
Can harbor seals (Phoca vitulina) discriminate familiar conspecific calls after long periods of separation?
}

\author{
Mila Varola ${ }^{\text {Equal first author, 1,2 }}$, Laura Verga ${ }^{\text {Corresp., Equal first author, 1, } 3 \text {, Marlene Sroka }}{ }^{2,4}$, Stella Villanueva ${ }^{2}$, Isabelle Charrier ${ }^{5}$, \\ Andrea Ravignani ${ }^{\text {Corresp. } 1,2}$ \\ ${ }^{1}$ Comparative Bioacoustics Research Group, Max Planck Institute for Psycholinguistics, Nijmegen, The Netherlands \\ 2 Research Department, Sealcentre Pieterburen, Pieterburen, the Netherlands \\ 3 Department of Neuropsychology and Psychopharmacology, Maastricht University, Maastricht, the Netherlands \\ 4 Department of Behavioral Biology, University of Münster, Münster, Germany \\ 5 Paris Saclay Institute of Neuroscience, Université Paris-Saclay, Orsay, France \\ Corresponding Authors: Laura Verga, Andrea Ravignani \\ Email address: laura.verga@mpi.nl, andrea.ravignani@mpi.nl
}

The ability to discriminate between familiar and unfamiliar calls may play a key role in pinnipeds' communication and survival, as in the case of mother-pup interactions. Vocal discrimination abilities have been suggested to be more developed in pinniped species with the highest selective pressure such as the otariids; yet, in some group-living phocids, such as harbor seals (Phoca vitulina), mothers are also able to recognize their pup's voice. Conspecifics' vocal recognition in pups has never been investigated; however, the repeated interaction occurring between pups within the breeding season suggests that long-term vocal discrimination may occur. Here we explored this hypothesis by presenting three rehabilitated seal pups with playbacks of vocalizations from unfamiliar or familiar pups. It is uncommon for seals to come into rehabilitation for a second time in their lifespan, and this study took advantage of these rare cases. A simple visual inspection of the data plots seemed to show more reactions, and of longer duration, in response to familiar as compared to unfamiliar playbacks in two out of three pups. However, statistical analyses revealed no significant difference between the experimental conditions. We also found no significant asymmetry in orientation (left vs. right) towards familiar and unfamiliar sounds. While statistics do not support the hypothesis of an established ability to discriminate familiar vocalizations from unfamiliar ones in harbor seal pups, further investigations with a larger sample size are needed to confirm or refute this hypothesis. 


\section{Can harbor seals (Phoca vitulina) discriminate}

2 familiar conspecific calls after long periods of

3 separation?

4 Mila Varola ${ }^{1,2}$, Laura Verga ${ }^{1,3 \#}$, Marlene Sroka $^{2,4}$, Stella Villanueva ${ }^{2}$, Isabelle Charrier ${ }^{5}$, Andrea

5 Ravignani ${ }^{1,2 \#}$

$7 \quad{ }^{1}$ Comparative Bioacoustics Research Group, Max Planck Institute for Psycholinguistics,

8 Nijmegen, The Netherlands

$9 \quad{ }^{2}$ Research Department, Sealcentre Pieterburen, Pieterburen, The Netherlands

$10{ }^{3}$ Faculty of Psychology and Neuroscience, Department NP\&PP, Maastricht University,

11 Maastricht, The Netherlands

$12{ }^{4}$ Department of Behavioral Biology, University of Münster, Münster, Germany

$13{ }^{5}$ Université Paris-Saclay, CNRS, UMR 9197, Institut des Neurosciences Paris-Saclay, 91405

14 Orsay, France

Corresponding Authors:

17 Laura Verga ${ }^{1,3}$, Andrea Ravignani ${ }^{1,2}$

18 Comparative Bioacoustics Research Group, Max Planck Institute for Psycholinguistics, 19 Wundtlaan 1, 6525 XD Nijmegen, The Netherlands

20 Email address: laura.verga@mpi.nl, andrea.ravignani@mpi.nl

21

22

23

24

\section{Abstract}

The ability to discriminate between familiar and unfamiliar calls may play a key role in pinnipeds' communication and survival, as in the case of mother-pup interactions. Vocal discrimination abilities have been suggested to be more developed in pinniped species with the highest selective pressure such as the otariids; yet, in some group-living phocids, such as harbor seals (Phoca vitulina), mothers are also able to recognize their pup's voice. Conspecifics' vocal recognition in pups has never been investigated; however, the repeated interaction occurring between pups within the breeding season suggests that long-term vocal discrimination may occur. Here we explored this hypothesis by presenting three rehabilitated seal pups with playbacks of vocalizations from unfamiliar or familiar pups. It is uncommon for seals to come into rehabilitation for a second time in their lifespan, and this study took advantage of these rare cases. A simple visual inspection of the data plots seemed to show more reactions, and of longer duration, in response to familiar as compared to unfamiliar playbacks in two out of three pups. However, statistical analyses revealed no significant difference between the experimental conditions. We also found no significant asymmetry in orientation (left vs. right) towards familiar and unfamiliar sounds. While statistics do not support the hypothesis of an established 
ability to discriminate familiar vocalizations from unfamiliar ones in harbor seal pups, further investigations with a larger sample size are needed to confirm or refute this hypothesis.

\section{Introduction}

\section{Long-term recognition in pinnipeds}

Long-term recognition, which incorporates the storage and subsequent retrieval of information, plays an active role in human and animal behavior and communication. Indeed, it may be key for the survival of a species to recognize items stored in memory, such as sounds or images, as advantageous or potentially harmful (e.g., Mendl et al. 2001). Within animal species, recognition is further believed to enhance the individuals' fitness, playing an active role in mate reunion, parental care, and territory control (Insley 2000). Like many other animals, pinnipeds consistently rely on long-term memory to communicate and to interact with their environment and several species show impressive long-term memory capacities for visual information, problem-solving strategies, and vocal recognition (McCulloch et al. 1999; Reichmuth Kastak and Schusterman 2002; Pitcher et al. 2010). The ability to recognize target individuals in the wild can provide a strong advantage in the context of high natural selective pressure, as for example in mother-pup recognition (Charrier 2020). However, long-term vocal recognition in pinnipeds has been suggested as an evolutionary by-product of strong maternal imprinting experienced during the rearing period rather than an adapted trait (Charrier et al. 2003). Research on northern fur seals (Callorhinus ursinus) showed that females and their pups were able to respond to each other's vocalizations even several years after weaning (Insley 2000). While other studies have demonstrated similar long-term memory in other otariid species (Charrier et al. 2003; Pitcher et al. 2010), comparable work in phocids is lacking. A possible reason for this deficiency may depend on differences in both reproductive and maternal strategies between the two pinniped families: otariids form moderate to high density breeding colonies, in which females frequently separate from their pups to forage at sea throughout the entire lactation; instead, most phocids are not colonial and females stay with their young until weaning (Hammill et al., 1991). These different strategies may impact mother-pup recognition, which has been suggested to be less needed in phocids than in otariids (Job et al. 1995; McCulloch et al. 1999; McCulloch and Boness 2000). Field observation suggests that recognition abilities may exist in phocid pups (Renouf et al. 1983; Lawson and Renouf 1987; Insley et al. 2003), but it has never been experimentally investigated.

\section{Harbor seal - a study model}

Harbor seals (Phoca vitulina) have a unique maternal strategy among phocids as females perform short foraging trips during lactation (Boness and Bowen 1996) while pups show high mobility and a tendency to gather during the breeding season (Sullivan 1982; Sauvé et al. 2015a). This maternal strategy implies frequent mother-pup separations, possibly requiring a strong need for an individual vocal recognition. Indeed, several preliminary studies have shown that pup vocalizations (known as mother-attraction calls, MACs) are individually distinctive by their fundamental frequencies, pup age, and sex, suggesting this as a key factor for pup 
79 recognition and for the maintenance of mother-offspring contact (Renouf 1984; Perry and

80 Renouf 1988; Khan et al. 2006). Eventually, in 2015, Sauvé and colleagues demonstrated that the

81 MACs of harbor seal pups contain individual vocal signatures (Sauvé et al. 2015b), and that

82 harbor seal mothers can recognize and distinguish the calls of their own pup by memorizing the

83 pup call signature (Sauvé et al. 2015a). However, similar evidence in pups is lacking as harbor

84 seal mothers do not vocalize, and whether they possess such ability is yet to be determined with

85 other conspecifics' calls.

86 As harbor seal pups spend the rearing period in close contact with other pups, they show their

87 most social behavior during this time. This close social proximity exposes them to conspecific

88 MACs from an early stage of life (Sullivan 1982; Bowen 1991) and could drive the development

89 of an individual recognition between familiar individuals. Such social recognition might reduce

90 aggressive interactions towards familiar individuals (Tripovich et al. 2008), as shown in grey

91 seal weaned pups (Robinson et al. 2015). In turn, the reduction of aggressive behaviors may limit

92 the pups' energy expenditure and may act as a driver for sociality and development of altruistic

93 behavior (Axelrod and Hamilton 1981). The frequent social interactions might be facilitated by

94 the strong site fidelity shown by harbor seals throughout the year (Cordes and Thompson 2015),

95 in turn promoting recognition of familiar individuals via acoustic, visual, and olfactory cues

96 (Robinson et al. 2015). However, memorization of conspecific vocalizations may not be a

97 functional target per se, but instead constitute a by-product of other potential memory capacities.

98 Conversely, one could hypothesize that harbor seal pups would not memorize conspecifics'

99 voices, either because of their young age or because this would not bring any advantage to their

100 own survival.

101 As a first, exploratory study, we aimed at testing whether it is possible for harbor seal pups to

102 discriminate between MACs from familiar and unfamiliar pups even after a long separation. To

103 this aim, we took advantage of the rare occasions in which already rehabilitated pups were

104 admitted into rehabilitation for a second time in their lifespan during their post weaning period.

105 During this second period, we presented three wild seal weaners with a playback sequence

106 composed of familiar and unfamiliar MACs and measured each animal's orientation and

107 behavioral response to these calls.

108

\section{Materials \& Methods}

110 Study site and animals

111 This research was performed at the Sealcentre Pieterburen, a seal rescue and rehabilitation center

112 in the Netherlands, which rehabilitates more than 150 phocids every year. The animals reached

113 the Sealcentre as pups in summer 2018 (cause: maternal separation). After a successful first

114 rehabilitation, three individuals returned to the center due to parasitic pneumonia, a relatively

115 common condition seen in young harbor seal weaners (winter 2018-2019). The three seals were

1167,8 , and 12 months old at the moment of the experiment, respectively (See Table 1). During

117 their first stay in rehabilitation, pups were housed with at least one companion and consistently

118 exposed to their companions' naturally emitted MACs. While harbor seals usually emit a 
119 considerable number of MACs as pups, they gradually stop vocalizing towards the end of the

120

121

122

123

124

125

126

127

128

129

130

131

132

133

134

135

136

137

138

139

140

141

142

143

144

145

146

147

148

149

150

151

152

153

154

155

156

157

158

weaning period, which occurs when they are 26-42 days old (Bowen 1991). Furthermore, they predominantly become solitary as weaners (Bowen 1991; Biolsi 2017). Social interactions between conspecific pups progressively increase with age, as it has been shown for social play behavior (Renouf and Lawson 1987). Since the subjects of the present study were released in the wild after the end of the weaning season, it is highly likely that they were not exposed to further MACs from any conspecific pup.

The first seal tested (seal-1) was a male, approximately 7-10 days old upon first arrival at the Sealcentre (Table 1). Seal-1 was housed during rehabilitation with several other pups, all females of the same age. The other two tested seals (seal-2 and seal-3) were each housed with only one companion. Seal-2 and its companion, both males, arrived at the Sealcentre as premature pups (5-6 and 3-4 days old, respectively). Seal-3 and its companion, both females, were about 7-10 days old at arrival. Age was determined by experienced veterinarians basing on the presence and appearance of the umbilical cord.

\section{Sound recordings}

Aerial vocalizations were recorded from each seal admitted at the Sealcentre during the health assessment upon intake, which occurred in summer 2017 and summer 2018. Twelve wild-born Eastern Atlantic harbor seals (Phoca vitulina vitulina) were recorded in 2017 and 2018 to build playback stimuli and three were tested in 2018 and 2019 with these playbacks. Recordings were taken with a Sennheiser ME-66 unidirectional microphone (frequency response of 40-20,000 Hz $\pm 2,5 \mathrm{~dB}$; Sennheiser electronic GmbH \& Co. KG, Wedemark, Germany) connected to a Zoom H6 digital recorder (Zoom Corporation, Tokyo, Japan). The sampling frequency of all recordings was $48 \mathrm{kHz}$ with 24-bit quantization, and they were saved as WAV files. An MZW-66 foam windshield was used to cover the microphone and protect it from water splashes. All pups admitted to rehabilitation were initially quarantined in pairs or groups, in acoustic contact with each other. Playback consisted of vocalizations recorded from MACs emitted by the test subjects' former quarantine companion(s) during summer 2018 (familiar MACs), and MACs from unknown pups recorded during summer 2017 (unfamiliar MACs).

\section{Playback procedure}

Each seal-specific playback was created using Praat 6.0.11 and consisted of a sequence of 8 blocks, each one containing 10 identical calls which onsets occurred every 6 seconds (Figure 1. See also Ravignani 2019). Half of the blocks consisted of familiar vocalizations ("companion"), while the other half consisted of unfamiliar vocalizations ("control"). To avoid possible habituation to sounds (Perry and Renouf 1988), blocks were separated by 3 minutes of silence. In addition, a silent period of minimum 60s was added before ("acclimation") and after ("postplayback") the playback presentation, to let the seal habituate to the new situation and to rest after the experiment. Since seal-1 shared its quarantine enclosure with several other pups, for the familiar vocalizations we selected calls from four companions; calls from each companion were grouped within a block and the order of blocks was randomized. The other two tested seals (seal2 and seal-3) each shared their quarantine with only one companion; therefore, the selected 
159 familiar vocalizations belonged to their respective companions. For each test subject, the seals

160

161

162

163

164

165

166

167

168

169

170

171

172

173

174

175

176

177

178

179

180

181

182

183

184

185

186

187

188

189

190

191

192

193

194

195

196

197

198

used as control were of the same sex and age as the companion(s). The alternation between companion and control blocks was randomized and presented in a different order to each seal (see Figure 1). Due to a technical problem, for one of the seals tested (seal-3), the first block of calls contained only 9 calls instead of 10 .

\section{Apparatus and experimental procedure}

Each harbor seal, once successfully rehabilitated and in good health condition, was exposed to a playback on the release day. The experiment was performed while the seal was in a box used to release the animal to prevent visual distractions. Particular care was taken to avoid external sources of noise during testing. Since rehabilitated seals were familiar with being transferred and weighed in tightly fitting boxes $(53 \times 123 \times 60 \mathrm{~cm})$, the effect of short periods of interaction with humans and confinement on the behavioral response was assumed to be negligible (Osinga and Hart 2010). The experiment was recorded with a Zoom Q8 camera, recording at 25 fps from the back side of the animal (i.e., behind its back flippers). The playback was broadcasted from a JBL Flip 2 speaker (frequency response $100 \mathrm{~Hz}-20 \mathrm{kHz}$ ), connected via cable to an iPhone 5S. The speaker was placed within a distance of $30 \mathrm{~cm}$ from the back of the box (see details below) and the sound pressure level was adjusted to simulate the sound pressure level of another seal pup located approximately 1-2 meters from the experimental subject. SPLs varied for each call to maintain their original natural amplitude at 1-2 meters, averaging $80 \mathrm{~dB}$ (measured with a CHECK MATE CM-130 sound level meter). Only after the equipment was in place and working, the playback was triggered remotely with the experimenter out of sight (Figure 2).

\section{Behavioral assessment}

Behavioral analyses and playback annotations were performed using BORIS (Behavioral Observation Research Interactive Software) v. 7.1.3 - 2018-11-16 (Friard and Gamba 2016). The anatomy of harbor seals affords a wide dynamic visual field; specifically, a seal performing eye movements can reach a visual field extending to $121^{\circ}$ on the dorsal side and $210^{\circ}$ in the horizontal plane (see Hanke et al. 2006 and figures therein); however, the dimensions of the experimental box only allowed the seals to turn their eyes or heads towards the sound source. Hence, we hypothesized that if seals could discriminate between familiar and unfamiliar voices, they would react to the broadcasted vocalizations by turning their heads towards the sound source placed behind them. We scored the behavioral reaction with a commonly used assay known as the orientation response (Insley 2000; Figure 3). To avoid any possible bias, all annotations were performed on the videos without sound and the annotator was blind to the experimental condition. Moreover, during sound playback experiments, scientists often noticed asymmetries in orientation (left vs. right) towards familiar and unfamiliar sounds in animals (Ghazanfar et al. 2001; Böye et al. 2005; Siniscalchi et al. 2012). The brain's left hemisphere controls vocal production and perception, and the recognition of a familiar sound (usually a conspecific call) generally corresponds to a predominant turn to the right side. Thus, we hypothesized that the seals would show different orientation parameters depending on the familiarity of the acoustic stimulus. We also hypothesized that a difference in the reaction to the

PeerJ reviewing PDF | (2021:07:63942:2:0:NEW 11 Oct 2021) 
199

200

201

202

203

204

205

206

207

208

209

210

211

212

213

214

215

216

217

218

219

220

221

222

223

224

225

226

227

228

229

230

231

232

233

234

235

236

237

238

sounds might be reflected in the look duration and in the time elapsed between playback onset and seal's first look to the sound source (latency). For example, a faster response (i.e. a shorter latency) and a longer look might be associated with a familiar vocalization. Thus, we measured three dependent variables: 1) number of looks, defined as either head turning at a $>90^{\circ}$ angle in the horizontal or dorsal plane or as an eye presentation to the camera; 2) duration of each look; 3 ) latency. Responses to individual calls within a block (duration $=60 \pm .001 \mathrm{~s}$ ) were summed (number of looks) or averaged (duration, latency) to provide a base for the analyses. This way, the analyses would show the seal's reaction to the type of calls overall, either familiar (companion) or unfamiliar (control). Only reactions that started after the beginning of the block were considered. Vocal responses were not uttered in the current experiment. For latency and duration, we conducted the analyses twice: first, we analyzed only durations and latencies corresponding to looks. This method led to a removal of data from 3 out of 24 blocks ( 2 companion blocks from seal-1, 1 control from seal-3) in which no looks occurred; therefore, we conducted the analysis again by including these blocks and inputting a minimal duration (0s) and maximum latency (60s). As there was no difference in the outcome of the statistical analyses, we report here only results based on latency and duration corresponding to looks.

\section{Statistical analyses}

All analyses were performed with RStudio version 1.3.959 (RStudio Team 2020) running R version 4.0.2 (R Core Team 2020). Results were deemed significant at an alpha level of .05. Fisher's exact tests (package stats) were performed on contingencies tables (one per seal) pitting the direction of reaction (left vs. right) against sound familiarity (companion vs. control) to test for possible turning asymmetries in response to familiar or unfamiliar vocalizations. In addition, pairwise-correlations (Spearman's rank coefficient) were conducted to evaluate the relation between dependent variables.

We employed generalized linear mixed models (GLMM; package lme4; Bates et al. 2015) to model the seals' reactions to the playback blocks. After checking for data dispersion (package blmeco) and based on Shapiro-Wilk tests and on visual inspection of boxplots, histograms, qqplots, and Cullen and Frey graph (package fitdistrplus) we concluded that the number of looks could be best approximated by a Poisson distribution (overdispersion parameter $<1.4$, package blmeco), while duration and latency were better described by Gamma distributions. For all three dependent variables, the statistical models included familiarity condition (companion vs. control) as fixed effect and seal ID as random effect. Details of the employed models are summarized in Table 3. Furthermore, we used principal component analysis (PCA; packages stats, factoextra) to transform the three response variables (number of looks, duration, latency) into a single global measure describing the strength of response to playback (McGregor 1992; see also Vehrencamp et al. 2003; Sauvé et al. 2015b). Principal component (PC) scores were computed for PCs with eigenvalues greater than 1. PC scores were fed into a linear mixed effects model with familiarity condition as fixed effect and seal ID as random effect.

For all mixed models, model fit was reported as coefficients of determination $\left(\mathrm{R}^{2}\right)$ calculated based on Nakagawa et al. 2017 (package performance); however, we cautioned on the 
239

240

241 Ethics approval

242 All focal individuals were kept in the Sealcentre Pieterburen, one of the biggest seal

243

244

245

246

247

248

249

250

251

252

253

254

255

256

257

258

259

260

261

262

263

264

265

266

267

268

269

270

271

272

273

274

275

276

277

278

interpretability of these coefficients for generalized linear models (Sotirchos et al. 2019; Piepho 2019).

rehabilitation centers in the Netherlands, for clinical reasons only. Data collection was noninvasive and adhered to the guidelines of the Association for the Study of Animal Behavior (Buchanan et al., 2012). All procedures were approved by the Sealcentre veterinarians. The animals were neither captured nor kept longer than necessary to run this study. The present study involved behavioral testing only and did not cause any distress or pain to the animals. After the study, the animals were released into the wild according to the regulations and protocols of the Sealcentre Pieterburen.

\section{Results}

\section{Descriptive analysis}

A summary of response patterns to playbacks is presented in Table 2 and Figure 4. Visual inspection of the data suggested that seal-1 seemed to look less often than the other two seals towards the sound source. In addition, seal-1 looked less often to companion blocks than controls, while the opposite pattern (more looks to companions relative to controls) was observed in seal-2 and seal-3. Still judging from visual inspection, latencies were longer in control blocks in seal-1 and seal-2. Duration of reactions visually resembled the pattern observed for the number of looks, with seal-1 showing looks of similar length for control and companion blocks, and seal-2 and seal-3 displaying longer looks towards companions.

Because seal-1 was exposed to calls from multiple companions, we looked more in depth whether it reacted differently to any of them (Figure 5). Seal-1 did not react at all to two companions, while the remaining two companions received 2 looks each. Controls received either 1 look, 3 looks, or 4 looks. For companions, durations were similar, while they were more variable for controls. Latencies were variable for all blocks.

\section{Lateralization of response and correlations}

For each seal, there was no statistical association between the familiarity of the sound and the side of the orienting response (Fisher's exact tests; seal-1: $\mathrm{OR}=.44, \mathrm{p}=1$; seal-2: $\mathrm{OR}=1.39, \mathrm{p}$ $=.73$; seal-3: OR $=.29, \mathrm{p}=.10$; Figure 6 ).

Spearman's rank correlation coefficient was calculated to test for correlations between the three dependent variables. We found a significant correlation between the number of looks and their duration ( $\mathrm{rs}=.82, \mathrm{p}<.001)$, while the other correlations were not significant (duration and latency: $r s=-.41, p=.063$; latency and number of looks: $r s=-.40, p=.065$ ). These results were confirmed when excluding seal-1 from the analyses (number of looks and duration, $\mathrm{rs}=165.68$, $\mathrm{p}<.001$; other $\mathrm{ps}>.56$ ).

\section{Mixed-effects models}

Generalized linear mixed-effects models were employed to statistically investigate behavioral differences between companion and control calls. GLMMs fitting a Poisson (for the number of 
279 looks) or gamma (for the duration and latency of reaction) model were used to predict the 280 number of looks based on familiarity condition (fixed effect) while accounting for variability in 281 each seal (random effect seal ID). No significant effects emerged from these analyses (Table 3). 282 Seal-1 was housed in different conditions and exposed to playbacks from multiple conspecifics.

283 For this reason, we ran the models the second time after excluding data from this seal (i.e., based 284 on the data from seal-2 and seal-3). Even in this case, we found no difference between responses 285 to companions and controls (Table 3).

286 Principal Component Analysis

287 Number of looks, duration, and latency were fed into a PCA to identify a single measure

288 summarizing the strength of response to playback. The first component accounted for $70 \%$ of the 289 variance with an eigenvalue $>1$ (loading coefficients: number of looks $=.64$, duration $=.62$, 290 latency $=-.45$ ). A positive $\mathrm{PC}$ score indicates a strong response towards the sound source. These

291

292

293

294

295

296

297

298

299

300

301

302

303

304

305

306

307

308

309

310

311

312

313

314

315

316

317

318 composite scores were fed into a linear mixed-effects model with familiarity condition as fixed effect and seal ID as random effect (Shapiro-Wilk: $\mathrm{W}=.94, \mathrm{p}=.222$; model: $\mathrm{pca} \sim$ familiarity condition + (1 | seal_id), class: Imer), with no significant outcome (familiarity condition: estimate $=-.79 ; \mathrm{SE}=.56, \mathrm{t}=-1.42, \mathrm{p}=.17 ; \mathrm{r}^{2}=.26 / .07 ;$ Figure 7$)$.

Repeating the analyses without including seal-1 yielded comparable results. The first component accounted for $62 \%$ of the variance with an eigenvalue $>1$ (loading coefficients: number of looks $=.68$, duration $=.66$, latency $=-.32$ ). This composite score was fed into a linear mixed-effects model with familiarity condition as fixed effect and seal ID as random effect (Shapiro-Wilk: W $=.94, \mathrm{p}=.315$; model: $\mathrm{pca} \sim$ familiarity condition $+(1 \mid$ seal_id $)$, class: 1mer $)$, with no significant outcome (familiarity condition: estimate $=-.91 ; \mathrm{SE}=.66, \mathrm{t}=-1.37, \mathrm{p}=.191, \mathrm{r}^{2}=$ $\mathrm{NA} / .112)$.

\section{Discussion}

The current study set out to explore the ability of harbor seals to discriminate between familiar and unfamiliar vocalizations. We capitalized on a rare opportunity: three seals were admitted for rehabilitation twice in a relatively short time (approximately 6 months), first as orphaned pups and later as weaners affected by parasitic pneumonia. Our observations are compatible with the idea that the playback of conspecific calls may modulate seal behavior (Tripovich et al. 2008), although they are not supported by statistical analysis. However, since the present study is, to our knowledge, the first of its kind, it was limited by logistical difficulties due to the particular conditions of seal recruitment. Thus, our results require further investigation.

\section{Difference in response: seal-1 vs seal-2 and seal-3}

Visual inspection of the graphs revealed that the first tested seal (seal-1) showed very little response to MACs compared to the other two seals and it seemed to respond more to unfamiliar vocalizations. This animal differed from the others for several reasons. First, during its stay at the Sealcentre, seal-1 shared an enclosure with many other pups, but physical contact with companions was prevented by fences. Conversely, seal-2 and seal-3 only had one companion each, with whom physical contact was possible. Second, seal-1 spent a shorter period with 
319

320

321

322

323

324

325

326

327

328

329

330

331

332

333

334

335

336

337

338

339

340

341

342

343

344

345

346

347

348

349

350

351

352

353

354

355

356

357

358

companions than seal-2 and seal-3 did (11-34 days in comparison to 45 and 48, see Table 1). The time elapsed between testing and seal-1's separation from its companions was also shorter than in the other two cases (only 190/191 days in comparison to 291 and 355). Third, seal-1, a male, was exposed to MACs belonging to pups of the opposite sex. In contrast, the other two seals were exposed to MACs belonging to pups of the same sex (male for seal-2 and female for seal3). We speculated that especially the first two points may have played a key role in the reduced response shown by seal-1: by spending its first rehabilitation period with many other vocalizing pups, the animal was exposed to a more diverse stimulation coming from different sources. Moreover, being physically isolated from the other companions, seal-1 did not socialize with any of them, and thus it could not use visual or olfactory cues to reliably attribute calls to a given individual and reinforce individual vocal recognition. Taken together, these observations may justify a decreased chance to become familiar with the individual companions' vocalizations. Seal-1 and seal-2, both males, seemed to react faster to familiar as compared to unfamiliar calls, while for seal-3, a female, the response speed appeared to be similar in all conditions. We hypothesize that such a diverse response between the animals can be related to various aspects of pinnipeds' social structure: males generally display more active behavior than females from an early stage of life (Bowen 1991; Schusterman 2008) and become aggressive towards other males during the mating season (Hayes et al. 2004). Moreover, harbor seals show strong site fidelity throughout the year (Cordes and Thompson 2015). Male seals able to discriminate between familiar and unfamiliar conspecifics would gain a strong advantage in terms of reproductive success and energy expenditure. The faster reaction shown by seal-1 and seal-2 towards familiar calls may be a sign of this ability. However, possibly due to the small sample size, we found no statistical evidence to reject the hypothesis of discrimination between call types. Future studies, considering aspects such as sex and number of familiar individual calls presented to each tested seal, might help clarifying these intriguing preliminary observations.

\section{Correlation between variables and head-turn asymmetry}

We observed a significant correlation between the number of looks and their duration: seals responded longer to these MACs which also elicited more looks. These results suggest that harbor seals do not respond equally to all conspecific vocalizations but despite that, unfortunately, we did not find any significant association between the seals' response and the type of MAC, whether familiar or not. Furthermore, we tested for possible response asymmetries: previous evidence consistently showed that the left-brain hemisphere is responsible for vocal production and perception in animals and humans (Ghazanfar et al. 2001; Siniscalchi et al. 2012); accordingly, asymmetries in head orientation towards familiar and unfamiliar sounds have been found in pinnipeds as well as other animals, with a predominant right-ear (left brain hemisphere) advantage for familiar calls (Böye et al. 2005). In pinnipeds, however, most of these studies do not discriminate between the familiarity of single individual calls; rather, they refer to all conspecific sounds as "familiar sounds". Since all playbacks in our study were conspecific calls, we focused on the difference between "truly" familiar seals (i.e., former rehabilitation companions) and unfamiliar pups (i.e., unknown seal pups with which the focal animal had no 
359

360

361

362

363

364

365

366

367

368

369

370

371

372

373

374

375

376

377

378

379

380

381

382

383

384

385

386

387

388

389

390

391

392

393

394

395

396

397

previous contact). We found no specific or overall statistical association. Several factors may contribute to this null result. First, this lack of association may be due to the small sample size. Second, it may reflect a true lack of lateralization. Third, it may relate to the fact that we only presented conspecifics' sounds, while a different result may have emerged if we had tested animals using heterospecific sounds as control stimuli. Nevertheless, this null result can inspire future research on head-asymmetry response to conspecifics vs. heterospecifics in harbor seals using a similar paradigm.

\section{Limitations and future directions}

Given the novelty of the topic addressed in the current study, the experimental design had many limitations. First and foremost, due to the unique testing conditions, we were only able to investigate three animals. This low number certainly limited our inferential statistics and, consequently, our conclusions are mostly based on pure observations. Moreover, the difference in number of companions between the first seal and the other two mirrored the difference in results. To alleviate this shortcoming, future studies targeting long-term discrimination under similar circumstances (for example in seal rehabilitation centers) should consider recording vocalizations from as many seal pups as possible during their first rehabilitation period. This way, it would be possible to maximize the chances of obtaining usable data in the event of a second intake at the same center. This approach would be helpful in at least three ways. First, a larger sample size would enable testing for additional factors that may influence discrimination, such as the sex of the pup and/or of the recorded seal, and combinations thereof. Second, vocal discrimination in one animal may be influenced by the number of its companions, as suggested by the differences observed between seal- 1 and the other two seals. Third, natural variability in the time passed between the first and the second admission might further inform on long-term discrimination capacities in harbor seals: is there a temporal gradient for familiar vocalizations? Do seals discriminate between conspecific vocalizations regardless of how much time has passed since they were heard? In this case, if we had had a larger sample size, we could have included elapsed time as a predictor of seal responsiveness to familiar voices in the model.

\section{Conclusions}

The current study aimed at investigating, for the first time, the ability of harbor seals to discriminate between familiar and unfamiliar conspecifics during puppyhood. The most parsimonious interpretation of our null results is that the seals do not possess this capacity. A possible reason for this absence of effect would be that conspecific calls were not biologically relevant and worth remembering. Alternative explanations for the absence of effect could be that our experiment was underpowered or not well-enough targeted to this species' ecology. Harbor seals are subject of increasing scientific work; empirical evidence on vocal learning, sound production, time perception, hearing, auditory memory, and social dynamics, to name a few, is growing (Heinrich et al. 2016; Ravignani et al. 2016; Kastelein et al. 2018; Wilson et al. 2018; Adams et al. 2020; Galatius et al. 2020; Heinrich et al. 2020; Torres Borda et al., 2021). Once a 
398

399

400

401

402

403

404

405

406

407

408

409

410

411

412

413

414

415

416

417

418

419

420

421

422

423

424

425

426

427

428

429

430

431

432

433

434

435

436

437

438

439

440

clearer socioecological picture is available, we hope that our experiment will be modified to properly target the threshold of long-term memory capacities in harbor seals.

\section{Acknowledgements}

The authors would like to thank all the veterinarians and seal nurses at the Sealcentre Pieterburen for their help and support in handling the seals and coordinating the experiment procedure in accordance with the releasing schedule. We are also grateful to all the researchers who recorded the original sounds used for playbacks, especially to Marianne de Heer Kloots, who helped us perform the experiment, Koen de Reus, who shared with us his study material, and Alice Lowry. We would also like to thank Jakub Wesecki for proofreading the manuscript.

\section{References}

Adams A, Vogl W, Dawson C, Raverty S, Haulena M, Skoretz SA (2020) Laryngeal and soft palate valving in the harbor seal (Phoca vitulina). J Exp Biol 223(20):jeb230201. https://doi.org/10.1242/jeb.230201

Axelrod R, Hamilton W (1981) The evolution of cooperation. Science (80- ) 211(4489):1390-1396. https://doi.org/10.1126/science.7466396

Bates DM, Mächler M, Bolker B, Walker S (2015) Fitting Linear Mixed-Effects Models Using lme4. J Stat Softw 67(1):48. https://doi.org/10.18637/jss.v067.i01

Biolsi KL (2017) Pinniped Life History BT - Encyclopedia of Animal Cognition and Behavior. In: Vonk J, Shackelford T (eds). Springer International Publishing, Cham, pp 1-16

Boness DJ, Bowen WD (1996) The Evolution of Maternal Care in Pinnipeds. Bioscience 46(9):645-654. https://doi.org/10.2307/1312894

Bowen WD (1991) Behavioural ecology of pinniped neonates. In: The Behaviour of Pinnipeds. Springer Netherlands, Dordrecht, pp 66-127

Böye M, Güntürkün O, Vauclair J (2005) Right ear advantage for conspecific calls in adults and subadults, but not infants, California sea lions (Zalophus californianus): hemispheric specialization for communication? Eur J Neurosci 21(6):1727-1732. https://doi.org/10.1111/j.1460-9568.2005.04005.x

Buchanan K, Burt de Perera T, Carere C, Carter T, Hailey A, Hubrecht R, Jennings D, Metcalfe N, Pitcher T, Peron F, Sneddon L, Sherwin C, Talling J, Thomas R, Thompson M (2012) Guidelines for the treatment of animals in behavioural research and teaching. Anim Behav 83(1):301-309. https://doi.org/10.1016/j.anbehav.2011.10.031

Charrier I (2020) Mother-Offspring Vocal Recognition and Social System in Pinnipeds. In: Aubin T, Mathevon N (eds) Coding Strategies in Vertebrate Acoustic Communication., Animal Sig. Springer Nature Switzerland, pp 231-246

Charrier I, Mathevon N, Jouventin P (2003) Vocal signature recognition of mothers by fur seal pups. Anim Behav 65(3):543-550. https://doi.org/10.1006/anbe.2003.2073

Cordes LS, Thompson PM (2015) Mark-resight estimates of seasonal variation in harbor seal abundance and site fidelity. Popul Ecol 57(3):467-472. https://doi.org/10.1007/s10144-015-0496-z

Friard O, Gamba M (2016) BORIS: a free, versatile open-source event-logging software for video/audio coding and live observations. Methods Ecol Evol 7(11):1325-1330. https://doi.org/10.1111/2041210X.12584

Galatius A, Teilmann J, Tougaard J, Dietz R (2020) Variation of Male-Male Aggression Patterns in Harbor Seals (Phoca vitulina). Aquat Mamm 46(2):119-123. https://doi.org/10.1578/AM.46.2.2020.119 
441

442

443

444

445

446

447

448

449

450

451

452

453

454

455

456

457

458

459

460

461

462

463

464

465

466

467

468

469

470

471

472

473

474

475

476

477

478

479

480

481

482

483

484

Ghazanfar AA, Smith-Rohrberg D, Hauser MD (2001) The Role of Temporal Cues in Rhesus Monkey Vocal Recognition: Orienting Asymmetries to Reversed Calls. Brain Behav Evol 58(3):163-172. https://doi.org/10.1159/000047270

Hammill MO, Lydersen C, Ryg M, Smith TG (1991) Lactation in the ringed seal Phoca hispida. Can J Fish Aquat Sci 48:2471-2476. http://dx.doi.org/10.1139/f91-288.

Hanke W, Römer R, Dehnhardt G (2006) Visual fields and eye movements in a harbor seal (Phoca vitulina). Vision Res 46(17):2804-2814. https://doi.org/10.1016/j.visres.2006.02.004

Hayes SA, Kumar A, Costa DP, Mellinger DK, Harvey JT, Southall BL, Le Boeuf BJ (2004) Evaluating the function of the male harbor seal, Phoca vitulina, roar through playback experiments. Anim Behav 67(6):1133-1139. https://doi.org/10.1016/j.anbehav.2003.06.019

Heinrich T, Dehnhardt G, Hanke FD (2016) Harbour seals (Phoca vitulina) are able to time precisely. Anim Cogn 19(6):1133-1142. https://doi.org/10.1007/s10071-016-1020-3

Heinrich T, Ravignani A, Hanke FD (2020) Visual timing abilities of a harbor seal (Phoca vitulina) and a South African fur seal (Arctocephalus pusillus pusillus) for sub- and supra-second time intervals. Anim Cogn 23(5):851-859. https://doi.org/10.1007/s10071-020-01390-3

Insley SJ (2000) Long-term vocal recognition in the northern fur seal. Nature 406(6794):404-405. https://doi.org/10.1038/35019064

Insley SJ, Phillips A V., Charrier I (2003) A review of social recognition in pinnipeds. Aquat Mamm 29(2):181-201. https://doi.org/10.1578/016754203101024149

Job DA, Boness DJ, Francis JM (1995) Individual variation in nursing vocalizations of Hawaiian monk seal pups, Monachus schauinslandi (Phocidae, Pinnipedia), and lack of maternal recognition. Can J Zool 73(5):975-983. https://doi.org/10.1139/z95-114

Kastelein RA, Helder-Hoek L, Terhune JM (2018) Hearing thresholds, for underwater sounds, of harbor seals (Phoca vitulina) at the water surface. J Acoust Soc Am 143(4):2554-2563. https://doi.org/10.1121/1.5034173

Khan CB, Markowitz H, McCowan B (2006) Vocal development in captive harbor seal pups, Phoca vitulina richardii: Age, sex, and individual differences. J Acoust Soc Am 120(3):1684-1694. https://doi.org/10.1121/1.2226530

Lawson JW, Renouf D (1987) Bonding and Weaning in Harbor Seals, Phoca vitulina. J Mammal 68(2):445-449. https://doi.org/10.2307/1381496

McCulloch S, Boness DJ (2000) Mother-pup vocal recognition in the grey seal (Halichoerus grypus) of Sable Island, Nova Scotia, Canada. J Zool 251(4):449-455

McCulloch S, Pomeroy PP, Slater PJB (1999) Individually distinctive pup vocalizations fail to prevent allosuckling in grey seals. Can J Zool 77(5):716-723. https://doi.org/10.1139/z99-023

McGregor PK (1992) Playback and Studies of Animal Communication. Springer US, Boston, MA

Mendl M, Burman O, Laughlin K, Paul E (2001) Animal memory and animal welfare. Anim Welf 10(SUPPL.)

Nakagawa S, Johnson PCD, Schielzeth H (2017) The coefficient of determination R 2 and intra-class correlation coefficient from generalized linear mixed-effects models revisited and expanded. J R Soc Interface 14(134):20170213. https://doi.org/10.1098/rsif.2017.0213

Osinga N, Hart P (2010) Harbour seals (Phoca vitulina) and rehabilitation. NAMMCO Sci Publ 8(0 SEArticles):355. https://doi.org/10.7557/3.2699

Perry E, Renouf D (1988) Further studies of the role of harbor seal (Phoca vitulina) pup vocalizations in preventing separation of mother-pup pairs. Can J Zool 66:934-938

PeerJ reviewing PDF | (2021:07:63942:2:0:NEW 11 Oct 2021) 
485

486

487

488

489

490

491

492

493

494

495

496

497

498

499

500

501

502

503

504

505

506

507

508

509

510

511

512

513

514

515

516

517

518

519

520

521

522

523

524

525

526

527

528

Piepho HP (2019) A coefficient of determination (R2) for generalized linear mixed models. Biometrical J 61(4):860-872. https://doi.org/10.1002/bimj.201800270

Pitcher BJ, Harcourt RG, Charrier I (2010) The memory remains: long-term vocal recognition in Australian sea lions. Anim Cogn 13(5):771-776. https://doi.org/10.1007/s10071-010-0322-0

R Core Team (2020) R: A Language and Environment for Statistical Computing

Ravignani A (2019) Timing of antisynchronous calling: A case study in a Harbor Seal Pup (Phoca vitulina). J Comp Psychol 133(2):272-277. https://doi.org/10.1037/com0000160

Ravignani A, Fitch WT, Hanke FD, Heinrich T, Hurgitsch B, Kotz SA, Scharff C, Stoeger AS, de Boer B (2016) What Pinnipeds Have to Say about Human Speech, Music, and the Evolution of Rhythm. Front Neurosci 10(JUN):274. https://doi.org/10.3389/fnins.2016.00274

Reichmuth Kastak C, Schusterman RJ (2002) Long-term memory for concepts in a California sea lion (Zalophus californianus). Anim Cogn 5(4):225-232. https://doi.org/10.1007/s10071-002-0153-8

Renouf D (1984) the Vocalization of the Harbor Seal Pup (Phoca-Vitulina) and Its Role in the Maintenance of Contact With the Mother. J Zool 202(APR):583-590

Renouf D, Lawson J. W. (1987) Quantitative aspects of harbor seal (Phoca vitulina) play. J Zool 212(2): 267-273. doi:10.1111/j.1469-7998.1987.tb05989.x

Renouf D, Lawson J, Gaborko L (1983) Attachment between Harbour seal (Phoca vitulina) mothers and pups*. J Zool 199(2):179-187. https://doi.org/https://doi.org/10.1111/j.1469-7998.1983.tb02089.x

Robinson KJ, Twiss SD, Hazon N, Moss S, Lonergan M, Pomeroy PP (2015) Conspecific recognition and aggression reduction to familiars in newly weaned, socially plastic mammals. Behav Ecol Sociobiol 69(8):1383-1394. https://doi.org/10.1007/s00265-015-1952-7

RStudio Team (2020) RStudio: Integrated Development Environment for R

Sauvé CC, Beauplet G, Hammill MO, Charrier I (2015a) Mother-pup vocal recognition in harbor seals: influence of maternal behaviour, pup voice and habitat sound properties. Anim Behav 105:109-120. https://doi.org/10.1016/j.anbehav.2015.04.011

Sauvé CC, Beauplet G, Hammill MO, Charrier I (2015b) Acoustic Analysis of Airborne, Underwater, and Amphibious Mother Attraction Calls by Wild Harbor Seal Pups (Phoca vitulina). J Mammal 96(3):591-602. https://doi.org/10.1093/jmammal/gyv064

Schusterman RJ (2008) Vocal learning in mammals with special emphasis on innipeds BT - The Evolution of Communicative Flexibility: Complexity, Creativity, and Adaptivity in Human and Animal Communication. Evol Commun Flex Complexity, Creat Adapt Hum Anim Commun :41-70

Siniscalchi M, Lusito R, Sasso R, Quaranta A (2012) Are temporal features crucial acoustic cues in dog vocal recognition? Anim Cogn 15(5):815-821. https://doi.org/10.1007/s10071-012-0506-x

Sotirchos ES, Fitzgerald KC, Crainiceanu CM (2019) Reporting of R 2 Statistics for Mixed-Effects Regression Models. JAMA Neurol 76(4):507. https://doi.org/10.1001/jamaneurol.2018.4720

Sullivan RM (1982) Agonistic Behavior and Dominance Relationships in the Harbor Seal, Phoca vitulina. J Mammal 63(4):554-569. https://doi.org/10.2307/1380260

Borda LT, Jadoul Y, Rasilo H, Casals AS, Ravignani A. (2021). Vocal plasticity in harbor seal pups. bioRxiv. https://doi.org/10.1101/2021.02.10.430617

Tripovich JS, Charrier I, Rogers TL, Canfield R, Arnould JPY (2008) Who goes there? Differential responses to neighbor and stranger vocalizations in male Australian fur seals. Mar Mammal Sci 24(4):941-948. https://doi.org/https://doi.org/10.1111/j.1748-7692.2008.00222.x

Vehrencamp SL, Ritter AF, Keever M, Bradbury JW (2003) Responses to playback of local vs. distant contact calls in the orange-fronted conure, Aratinga canicularis. Ethology 109(1):37-54.

PeerJ reviewing PDF | (2021:07:63942:2:0:NEW 11 Oct 2021) 
529 https://doi.org/10.1046/j.1439-0310.2003.00850.x

530 Wilson, Susan C, Jones, Kayleigh A (2018) Behaviour of harbor seal (Phoca vitulina vitulina) mother-pup 531 pairs in Irish Sea intertidal habitats. JSTOR 118B(1):13-27. https://doi.org/10.3318/BIOE.2018.02 
Figure 1

Experimental design

The playback consisted of 8 blocks, each one including a sequence of 10 identical calls. Four of the blocks contained calls belonging to the former companions of the tested seal, while the remaining four consisted of unfamiliar pups' calls to serve as controls. Every call unit lasted 6 seconds and between every block there were 3 minutes of silence. Silent periods were added at the beginning and end of the playback ("acclimation" and "post-playback"). The order of the blocks was randomized and was different for each tested seal.

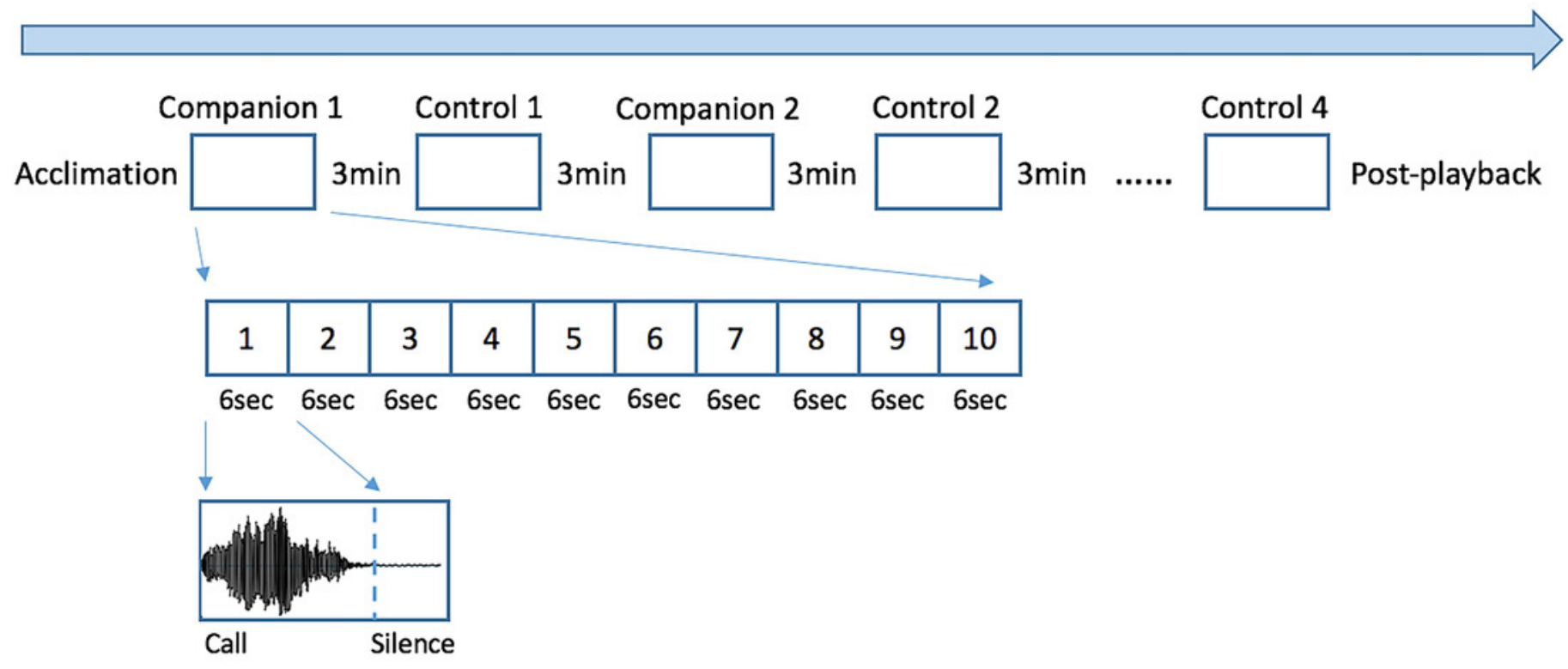


Figure 2

Overview of the experimental area and set-up.

(a) The experiment area is isolated so that the seal is not distracted by external visual stimuli. (b) The camera is placed behind the seal and the speaker is placed $30 \mathrm{~cm}$ from the box. (c) Additional light is provided by a lamp, to guarantee a clear image.
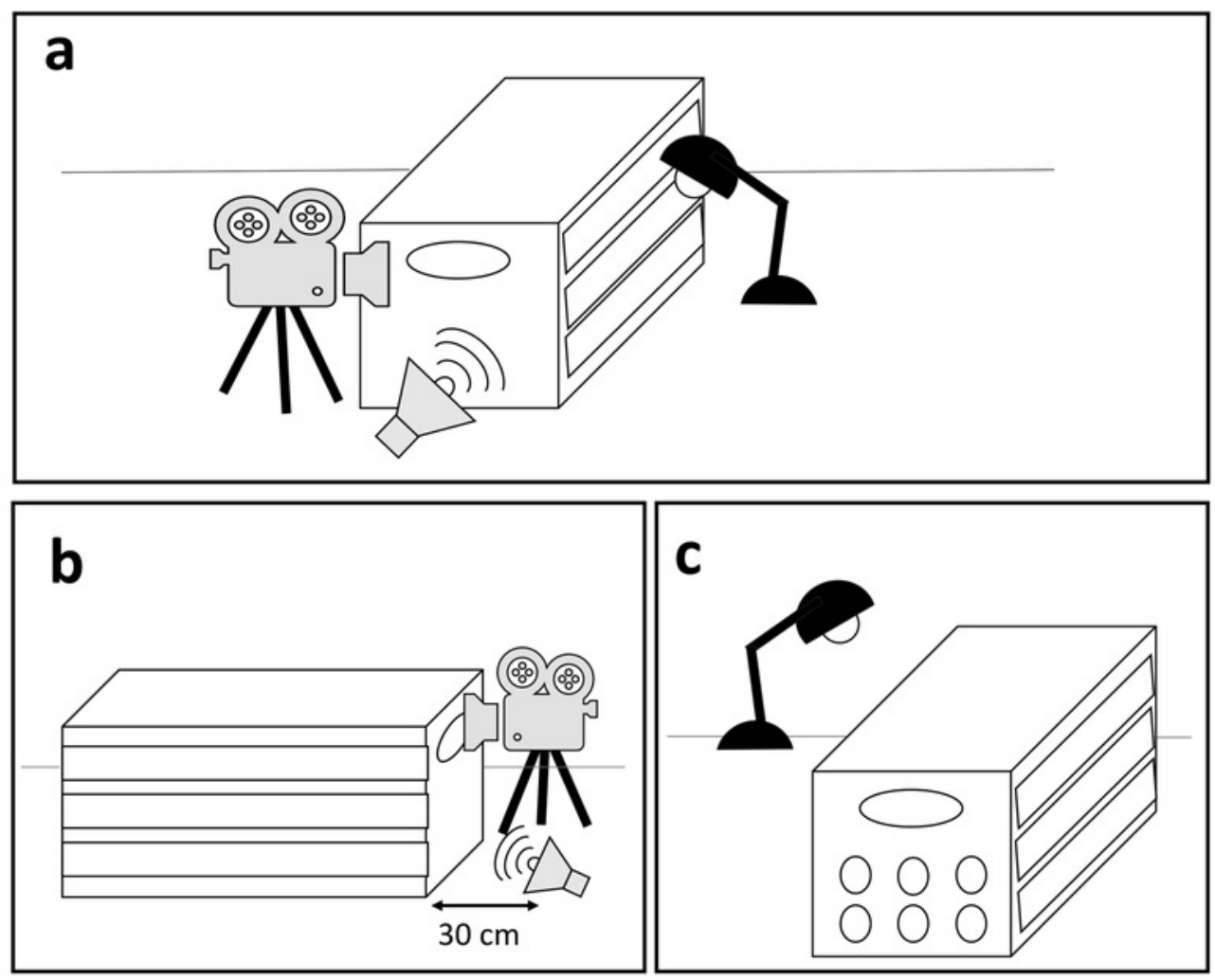
Figure 3

Representation of the recorded behavioral response.

(A) eye presentation, the seal turns its head at an angle of $<90^{\circ}$; (B) head turn, the seal rotates its head towards the sound source at an angle of $>90^{\circ}$. 

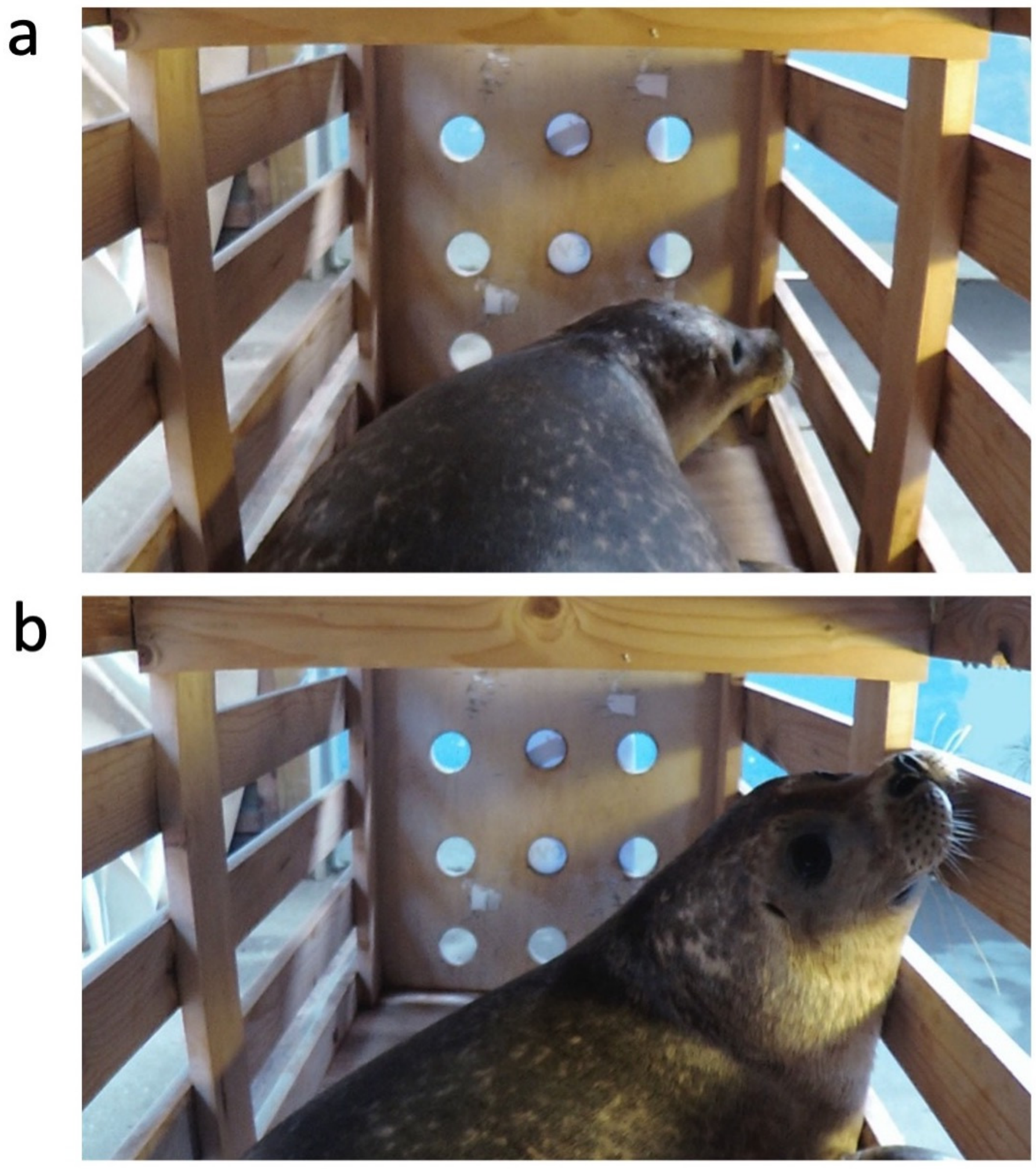
Figure 4

Graphic summary of the experimental results.

Boxplots showing the number of looks (A), their latency (B), and duration (C) for familiar (companion) relative to unfamiliar (control) blocks. For all variables, the box contains the interquartile range (i.e., the range containing $50 \%$ of all observations) and the median value (middle line), while the whiskers represent values extending outside $50 \%$ of the observations.
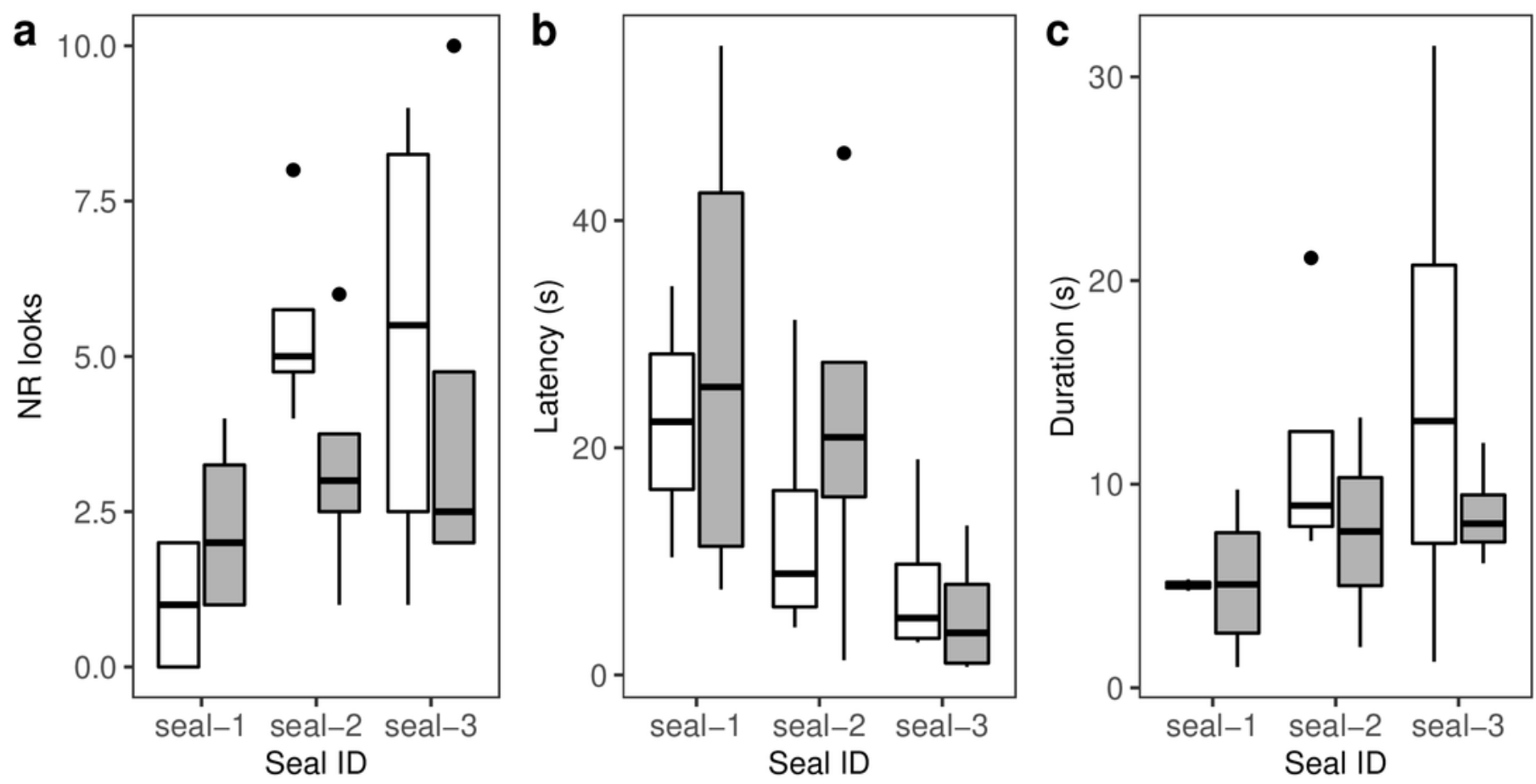

Familiarity companion control 
Figure 5

Details of seal-1 responses to playback.

Panels depict the number of looks (a), latency (b), and duration (c) for each block to either familiar (companion) or unfamiliar (control) blocks.
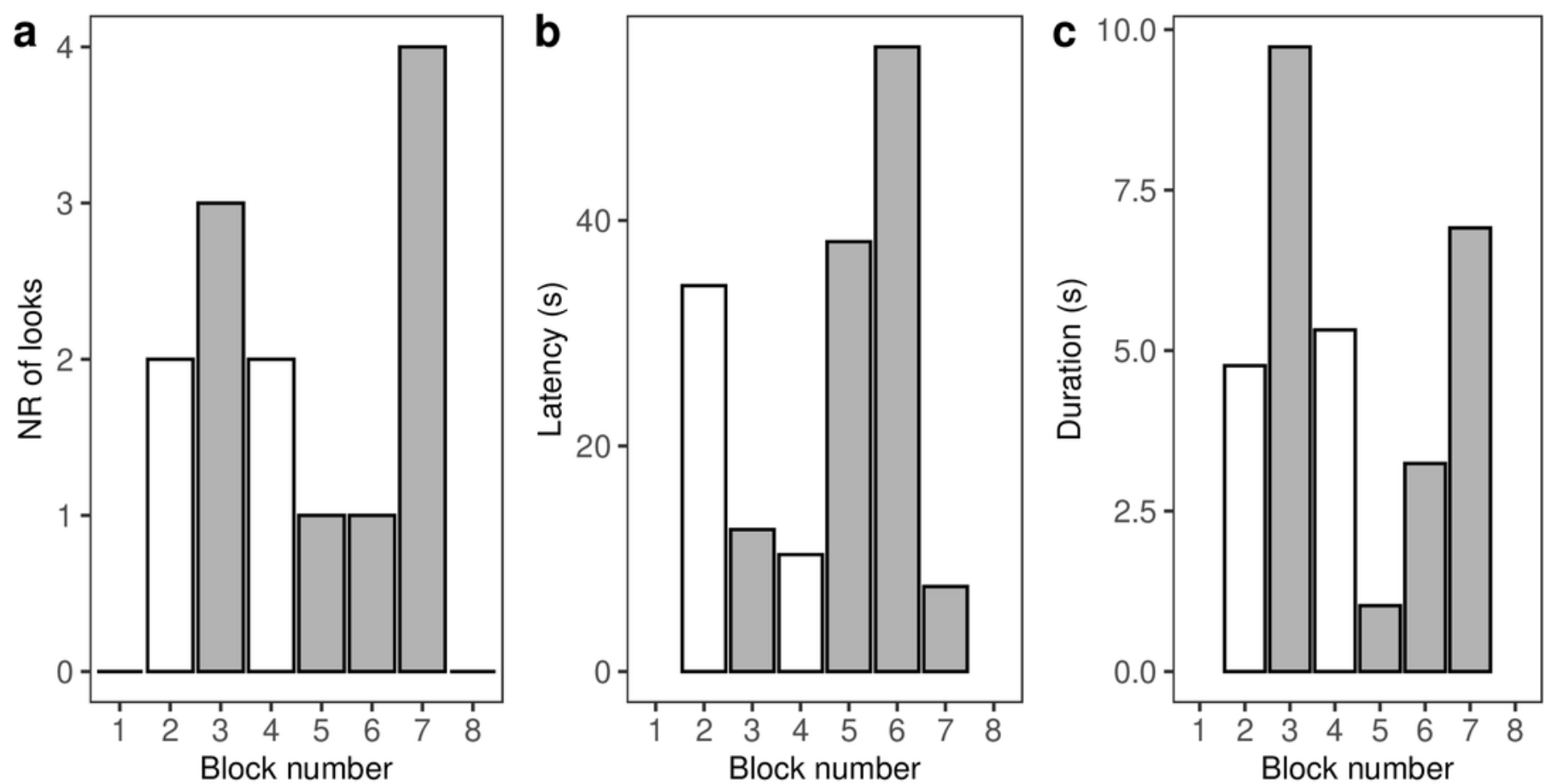

Familiarity $\square$ companion $\square$ control 
Figure 6

Pattern of lateralization for the observed behaviors.

The graph depicts, for each seal, the direction of each head turn (i.e., left or right) in response to either familiar (i.e., companion) or unfamiliar (i.e., control) vocalizations.

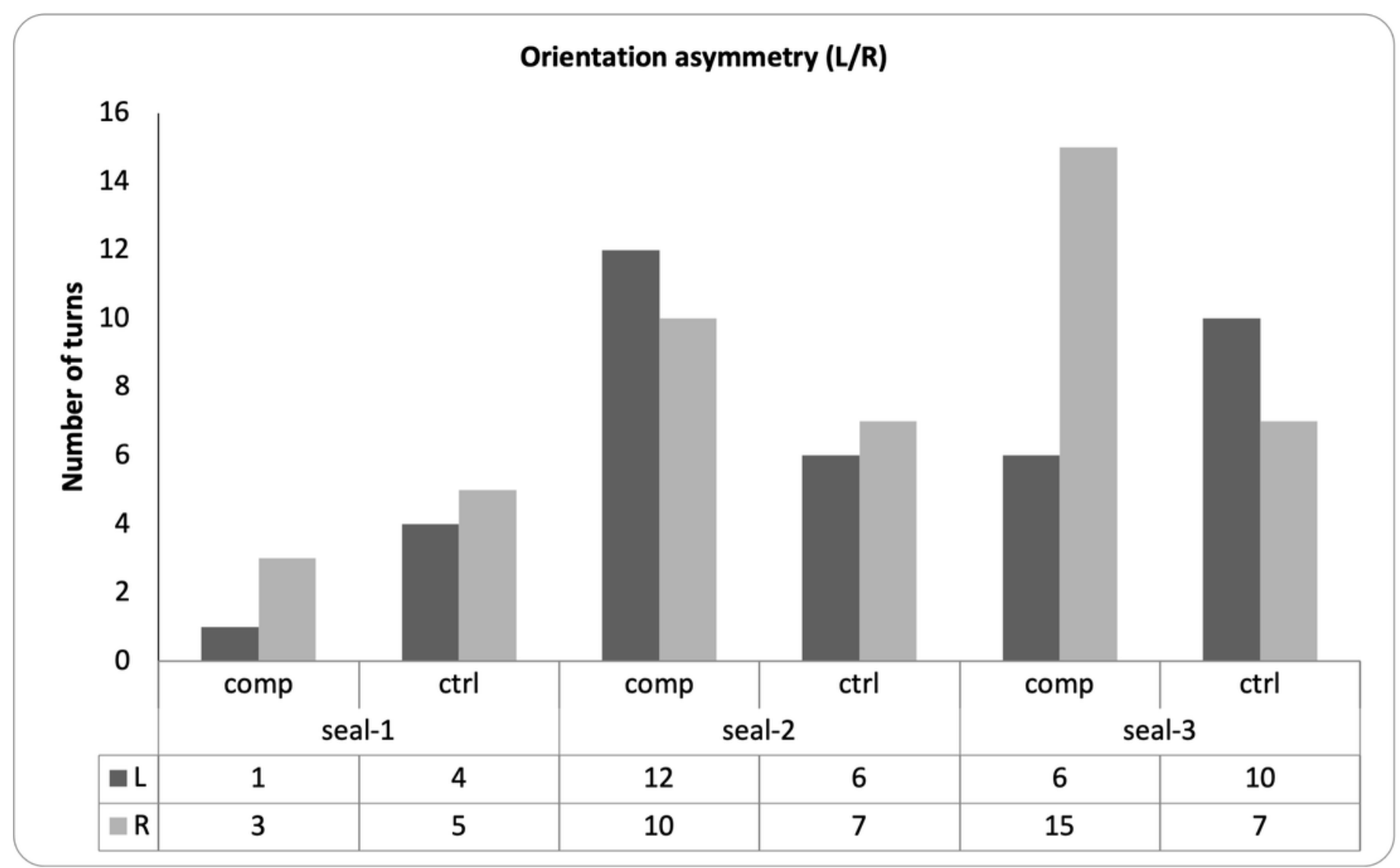


Figure 7

PCA results.

Principal component scores (PC1) of pups' behavioural responses to calls from their companion and those from control (unfamiliar individuals). For all variables, the box contains the interquartile range (i.e., the range containing $50 \%$ of all observations) and the median value (middle line), while the whiskers represent values extending outside $50 \%$ of the observations.

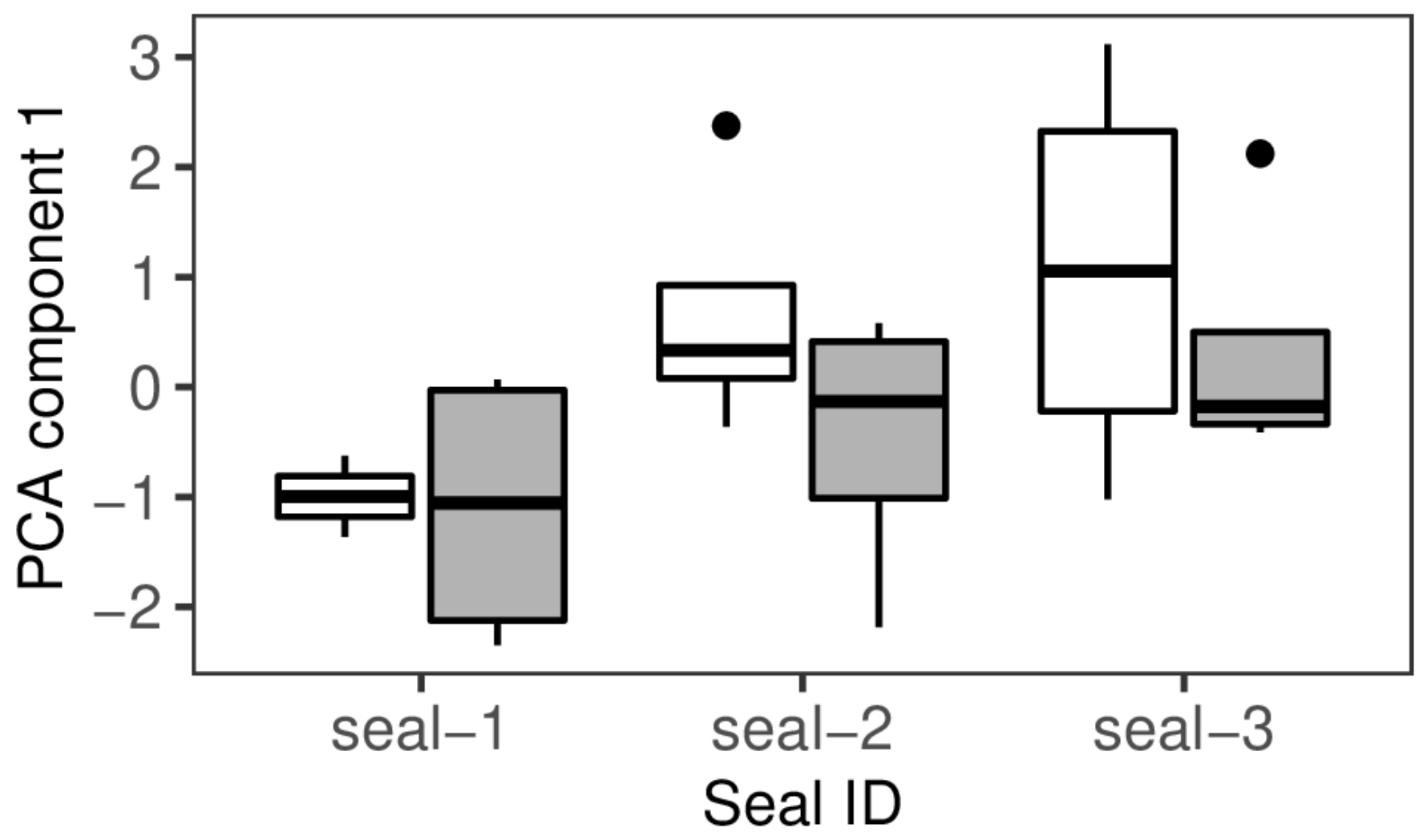

Familiarity 追 companion 追 control 


\section{Table $\mathbf{1}$ (on next page)}

Characteristics of the seals tested.

The first column shows the name and the sex of the three tested seals. The following three columns respectively refer to the date of the first admission (cause: maternal separation), the estimated seal age at the first admission, and the age and sex of its companion(s). The last columns show how much time the housemates spent together, how much time passed between their meeting and the experiment, and how much time passed between the test and the pups' separation (time units are expressed in days). For seal-1, the details of each of the four companions (c1, c2, c3, c4) are provided separately. 
1

\begin{tabular}{|c|c|c|c|c|c|c|}
\hline $\begin{array}{l}\text { Seal ID } \\
\text { and sex }\end{array}$ & $\begin{array}{c}\text { First } \\
\text { arrival } \\
- \\
\text { Estimated } \\
\text { age }\end{array}$ & $\begin{array}{l}\text { Age and sex of } \\
\operatorname{companion}(s)\end{array}$ & $\begin{array}{c}\text { Test date } \\
- \\
\text { Estimated } \\
\quad \text { age }\end{array}$ & $\begin{array}{c}\text { Days with } \\
\text { companion } \\
\text { (s) }\end{array}$ & $\begin{array}{c}\Delta \text { Time } \\
\text { (test-meeting) }\end{array}$ & $\begin{array}{c}\Delta \text { Time } \\
\text { (test-separation) }\end{array}$ \\
\hline $\begin{array}{c}\text { seal-1 } \\
\mathrm{M}\end{array}$ & $\begin{array}{c}\text { 26/06/2018 } \\
- \\
7-10 \text { days }\end{array}$ & $\begin{array}{c}\text { all companions: } \\
7-10 \text { days } \\
\text { F }\end{array}$ & $\begin{array}{c}\text { 03/01/2019 } \\
- \\
\text { ca } 7 \text { months }\end{array}$ & $\begin{array}{l}\mathrm{c} 1: 22 \\
\mathrm{c} 2: 11 \\
\mathrm{c} 3: 23 \\
\mathrm{c} 4: 34\end{array}$ & $\begin{array}{l}\mathrm{c} 1: 190 \\
\mathrm{c} 2: 191 \\
\mathrm{c} 3: 191 \\
\mathrm{c} 4: 191\end{array}$ & $\begin{array}{l}\mathrm{c} 1: 168 \\
\mathrm{c} 2: 180 \\
\mathrm{c} 3: 168 \\
\mathrm{c} 4: 157\end{array}$ \\
\hline $\begin{array}{l}\text { seal-2 } \\
\mathrm{M}\end{array}$ & $\begin{array}{c}\text { 22/05/2018 } \\
- \\
5-6 \text { days } \\
\text { (premature) }\end{array}$ & $\begin{array}{c}\text { 3-4 days } \\
\text { (premature) } \\
\text { M }\end{array}$ & $\begin{array}{c}\text { 10/03/2019 } \\
- \\
\text { ca } 8 \text { months }\end{array}$ & 45 & 291 & 246 \\
\hline $\begin{array}{l}\text { seal-3 } \\
\text { F }\end{array}$ & $\begin{array}{c}\text { 24/06/2018 } \\
- \\
7-10 \text { days }\end{array}$ & $\begin{array}{c}\text { 7-10 days } \\
\text { F }\end{array}$ & $\begin{array}{c}\text { 16/06/2019 } \\
- \\
\text { ca } 12 \text { months }\end{array}$ & 48 & 355 & 307 \\
\hline
\end{tabular}

2

3

4 


\section{Table 2 (on next page)}

Descriptive summary of individual seals' responses to blocks.

Responses are reported as total count of looks, their average latency and duration, for all conditions, companions (abbreviation: comp), and controls (abbreviation: cont). Standard deviations are reported in brackets. 
1

\begin{tabular}{|c|c|c|c|c|c|c|}
\hline Seal ID & \multicolumn{2}{|c|}{ Number of Looks } & \multicolumn{2}{|c|}{ Latency } & \multicolumn{2}{|c|}{ Duration } \\
\hline \multirow{2}{*}{ seal-1 } & \multirow{2}{*}{13} & comp:4 & \multirow{2}{*}{$\begin{array}{c}26.37 \\
(19.20)\end{array}$} & $\begin{array}{c}\text { comp:22.29 } \\
(16.87)\end{array}$ & \multirow{2}{*}{$\begin{array}{c}5.17 \\
(3.00)\end{array}$} & $\begin{array}{c}\text { comp:5.04 } \\
(0.39)\end{array}$ \\
\hline & & cont:9 & & $\begin{array}{c}\text { cont:28.41 } \\
(22.43)\end{array}$ & & $\begin{array}{c}\text { cont:5.23 } \\
(3.86)\end{array}$ \\
\hline \multirow{2}{*}{ seal-2 } & \multirow{2}{*}{35} & comp:22 & \multirow{2}{*}{$\begin{array}{c}17.80 \\
(15.21)\end{array}$} & $\begin{array}{c}\text { comp:13.32 } \\
(12.31)\end{array}$ & \multirow{2}{*}{$\begin{array}{c}9.61 \\
(5.66)\end{array}$} & $\begin{array}{c}\text { comp: } 11.56 \\
(6.45)\end{array}$ \\
\hline & & cont: 13 & & $\begin{array}{c}\text { cont:22.28 } \\
(18.30)\end{array}$ & & $\begin{array}{c}\text { cont:7.66 } \\
(4.80)\end{array}$ \\
\hline \multirow{2}{*}{ seal-3 } & \multirow{2}{*}{38} & comp:21 & \multirow{2}{*}{$\begin{array}{c}6.64 \\
(6.38)\end{array}$} & $\begin{array}{c}\text { comp:7.97 } \\
(7.53)\end{array}$ & \multirow{2}{*}{$\begin{array}{l}11.66 \\
(9.23)\end{array}$} & $\begin{array}{c}\text { comp: } 14.75 \\
(12.93)\end{array}$ \\
\hline & & cont: 17 & & $\begin{array}{c}\text { cont: } 5.31 \\
(5.80)\end{array}$ & & $\begin{array}{c}\text { cont: } 8.57 \\
(2.52)\end{array}$ \\
\hline
\end{tabular}

2

3

4

5 


\section{Table 3(on next page)}

Summary of the mixed effect models and corresponding results.

The statistical models were applied first on the three seals together (top rows), and then excluding seal-1 from the group (bottom rows). 


\begin{tabular}{|c|c|c|c|c|c|c|}
\hline & Response & Predictors & Estimate & SE & $\mathbf{z}$ & p-value \\
\hline \multirow{6}{*}{$\begin{array}{l}\text { All } \\
\text { seals }\end{array}$} & \multirow{2}{*}{$\begin{array}{l}\text { Number of } \\
\text { looks }\end{array}$} & familiarity: control & -.19 & .22 & -.87 & .39 \\
\hline & & \multicolumn{5}{|c|}{$\begin{array}{l}\text { Model: } n r . \text { of looks } \sim \text { familiarity }+(1 \mid \text { seal_id }), \text { class Glmer, family Poisson, link: } \log , \mathrm{R}^{2} \\
\text { conditional/marginal }=.40 / .02\end{array}$} \\
\hline & \multirow[t]{2}{*}{ Duration } & familiarity: control & .05 & .03 & 1.49 & .14 \\
\hline & & \multicolumn{5}{|c|}{$\begin{array}{l}\text { Model: duration } \sim \text { familiarity }+(1 \mid \text { seal_id }) \text {, class: Glmer, family: Gamma, link: inverse, } \mathrm{R}^{2} \\
\text { conditional/marginal }=.002 / .002\end{array}$} \\
\hline & \multirow[t]{2}{*}{ Latency } & familiarity: control & -.02 & .03 & -.68 & .50 \\
\hline & & \multicolumn{5}{|c|}{$\begin{array}{l}\text { Model: latency } \sim \text { familiarity }+(1 \mid \text { seal_id }), \text { class: Glmer, family: Gamma, link: inverse, } \mathrm{R}^{2} \\
\text { conditional/marginal }=.001 / .000\end{array}$} \\
\hline \multirow{6}{*}{$\begin{array}{l}\text { Seals } \\
2 \text { and } 3\end{array}$} & \multirow{2}{*}{$\begin{array}{l}\text { Number of } \\
\text { looks }\end{array}$} & familiarity: control & -.36 & .24 & -1.51 & .13 \\
\hline & & \multicolumn{5}{|c|}{$\begin{array}{l}\text { Model: nr. of looks } \sim \text { familiarity }+(1 \mid \text { seal_id }) \text {, class Glmer, family Poisson, link: } \log , \mathrm{R}^{2}= \\
\text { NA/.148 }\end{array}$} \\
\hline & \multirow[t]{2}{*}{ Duration } & familiarity: control & .05 & .03 & 1.46 & .15 \\
\hline & & \multicolumn{5}{|c|}{$\begin{array}{l}\text { Model: duration } \sim \text { familiarity }+(1 \mid \text { seal_id }) \text {, class: Glmer, family: Gamma, link: inverse, } \mathrm{R}^{2} \\
\text { conditional/marginal }=\mathrm{NA} / .002\end{array}$} \\
\hline & \multirow[t]{2}{*}{ Latency } & familiarity: control & -.02 & .04 & -.52 & .60 \\
\hline & & \multicolumn{5}{|c|}{$\begin{array}{l}\text { Model: latency_react } \sim \text { familiarity }+(1 \mid \text { seal_id }), \text { class: Glmer, family: Gamma, link: inverse, } \\
\mathrm{R}^{2} \text { conditional } / \text { marginal }=.001 / .000\end{array}$} \\
\hline
\end{tabular}

2

3 